\title{
Evidence for Age-Related Equivalence in the Directed Forgetting Paradigm
}

\author{
Nadia Gamboz* and Riccardo Russo $\dagger$ \\ *Department of Psychology, University of Trieste, Italy, †Department of Psychology, University \\ of Essex, United Kingdom
}

\begin{abstract}
The directed forgetting paradigm involves, under particular experimental circumstances, inhibitory mechanisms, which operate to the successful forgetting of irrelevant words. The item-by-item cueing method (e.g., Basden \& Basden, 1996) was used to investigate the directed forgetting effect in young and old adults. Processing of the experimental words was manipulated between subjects by asking participants to perform either a deep or a shallow orienting task on each word of the study list before the occurrence of the cue (to remember of to forget). Results indicated that the instruction to process deeply both to-be-remembered and to-beforgotten words led to equivalent directed forgetting effects in young and old adults. These results are discussed with respect to the implications they have for the Inhibitory Deficit theory (e.g., Hasher \& Zacks, 1988), which suggests that cognitive aging is mainly characterized by a reduction in the efficiency of inhibitory processes. (C) 2002 Elsevier Science (USA)
\end{abstract}

\section{INTRODUCTION}

The directed forgetting paradigm consists of presenting a list of words, some of which must be remembered (TBR) for a later memory test, and others that are to be forgotten (TBF). Each word in the list can be individually cued to be forgotten or to be remembered immediately after its presentation (item-by-item cueing method) or a single, unexpected cue to forget can be presented half way through the list (list cueing method). In this second case participants are told to forget the preceding words and to concentrate on remembering the upcoming words. When, after a retention interval, young adults are asked to recall as many words as they can, both TBR and TBF words, they recall significantly more TBR words than TBF words. This effect is known as the directed forgetting effect and is widely assumed to reflect the fact that either processing or retrieval of the TBF words has been suppressed, so that their later retrieval is impaired compared to retrieval of the target TBR words (e.g., Basden \& Basden, 1996; Basden, Basden, \& Gargano, 1993; Golding, Long, \& MacLeod, 1994).

The assumption that the directed forgetting paradigm involves inhibitory mechanisms has been important for the Inhibitory Deficit theory put forward by Hasher and Zacks (1988; Zacks \& Hasher, 1994), suggesting that cognitive aging is mainly characterized by a reduction in the efficiency of inhibitory processes. In line with the inhibitory framework, recently Zacks, Radvansky, and Hasher (1996) found, using different directed forgetting procedures and material, smaller directed forgetting effects in old compared with young adults. More precisely, young adults recalled overall more TBR and TBF words than older adults and both age groups recalled more TBR words than TBF words, but the difference between the two word types was smaller for the elderly than for young adults. Zacks et al. interpreted their results as evidence that old adults are less able than young adults to suppress the processing of the items designed to be irrelevant (by the forget cue).

Zacks et al.'s (1996) conclusion may, however, be premature. In fact, very recent studies using the list cueing method reported equivalent directed forgetting effects in the two age groups (Gamboz, 2000; Moulin, Macrae, \& North, 2000, Experiment 1). These findings clearly challenge the assumption that a generalized 
inhibitory deficit is the major factor responsible for Zacks et al.'s (1996) results of smaller directed forgetting effects in old than in young adults. In the light of these new findings, we suggest that age-related differences in other mechanisms, rather than in inhibition, led to the findings of smaller directed forgetting effects in the elderly compared to young adults when the item-by-item cueing procedure was used (Zacks et al., 1996, Experiments 1A and 1B). Precisely, given that the itemby-item cueing method encourages selective processing of TBR words which promotes a more elaborate encoding of these word at the expenses of TBF words (e.g. Basden et al., 1993), the significant interactions between age and word type (TBR vs TBF), indicating smaller directed forgetting in old than in young adults, may resemble the well documented age $\times$ level of processing interaction (e.g., Erber, Herman, \& Botwinick, 1980). That is, the age $\times$ word type interactions found using the item-by-item cueing method may reflect larger age differences in recall of words processed extensively (the TBR words) compared to recall of words processed only superficially (the TBF words), occurring as a consequence the well documented age-related episodic memory deficit (e.g., Light, 1991). This hypothesis is consistent with the recent findings of equivalent directed forgetting effect using the list cueing method. The lack of significant interactions between age and word type using the list cueing procedure may indicate that, when both TBR and TBF receive an equivalent and elaborate processing (because participants are unaware of the occurrence of a forget cue midway through the study list) old adults recall overall fewer words than young adults due to their episodic memory deficit, but the difference between recall of TBR and TBF words is equivalent in young and old adults due to the operation of similar memory inhibition processes in the two age groups.

The experiment described in this paper aimed to test empirically the above hypothesis by manipulating, between subjects, the level of processing of individually cued words included in the study list before the occurrence of a cue to remember of to forget. We expected young and old adults who processed selectively the TBR words to show different directed forgetting effects, smaller in old than in young adults, replicating Zacks et al.'s (1996) results, but similar directed forgetting effects in young and old who initially processed extensively both TBR and TBF words.

\section{EXPERIMENTAL INVESTIGATION}

In this experiment, the words were individually cued and the level of processing was manipulated between subjects by asking participants either to judge the pleasantness of each word or to count the number of letters in a word. These two different orienting tasks were assumed to promote deep and shallow processing, respectively. In fact, judging the pleasantness of each word should induce participants to encode deeply these words, that is, in terms of their meanings, whereas counting the number of letters in a word does not necessarily require the participants to go beyond a perceptual analysis of that word. Participants in a third control group did not receive any particular processing instruction. The deep processing condition intended to resemble the type of processing that $\mathrm{TBR}$ and $\mathrm{TBF}$ words receive when the list cueing method is used, whereas the shallow processing condition should be equivalent to the normal condition under the item-by-item cueing. In fact, in both the shallow and control processing conditions, both TBR and TBF words are processed only superficially before the cue appears, but participants should then engage in more elaborate processing of the words cued to be remembered. 


\section{METHOD}

\section{Participants}

Thirty young and 30 old English adults participated in this experiment. Young participants $(M=22$ years of age) were undergraduate psychology students at the University of Essex. Older adults ( $M=68$ years of age) were mainly members of the Essex University of the Third Age and of different local associations. Young adults had significantly more years of education $(M=15$ years of education) than old adults $(M=13$ years of education). However, older adults showed significantly higher verbal IQ scores $(M=120)$, as measured by the National Adult Reading Test (Nelson \& O'Connell, 1978) than did young adults $(M=114)$.

\section{Material}

The material consisted of 56 words selected from the Kucera and Francis (1967) norms. These words were organized in two lists of 28 words, matched for word frequency $(M \mathrm{~s}=76.2$ and 73.9$)$ and word length $(M \mathrm{~s}=5.3$ and 5.5). Each list was randomly assigned to five young and five old adults in each processing condition, so that a total of 15 young and 15 old adults received one list and the remaining 15 young and 15 old adults received the other list. The order of word presentation within a list and the remember-forget cue assigned to each word in a list was randomized for each participant. There were 14 TBR and 14 TBF words. The first and last two words in each list were used as buffer words to minimize primacy and recency effects and were excluded from the analysis. Two of these words were TBR and two TBF words.

\section{Procedure}

The words were printed in Times font, size 20. Each word was individually presented at the center of a computer screen for $5 \mathrm{~s}$ and was followed by either an $\mathrm{R}$ (the remember cue) or by an F (the forget cue), which remained on the screen for $1 \mathrm{~s}$. Participants were instructed to remember only the words followed by an R. According to whether participants were assigned to the shallow or deep processing instructions, they were also asked to count the number of letters in each word appearing on the screen or to read aloud each word and to judge its pleasantness. After all the words in the list had been presented, participants counted backward by steps of three digits for $30 \mathrm{~s}$ and then they were asked to write down as many TBR and TBF words as they could remember. There was not a limit of time for completing the free recall task.

The experiment started with a six-word practice list to familiarize participants with the procedure (the instruction for the practice list were consistent with the experimental group each participant was assigned to) and ended with the National Adults Reading Test.

\section{Design}

The experiment included a two-level (Age: Young vs Old) and a three-level (Processing: Deep vs Shallow vs Control) between-subjects variables. Participants were randomly assigned to one of the three experimental conditions. Word type (TBR vs $\mathrm{TBF}$ ) was manipulated within subjects. The dependent variable was the percentage of recall of TBR and TBF words. 
TABLE 1

Mean Percentage of TBR and TBF Recalled, According to Age Group,

Word Type, and Level of Processing

\begin{tabular}{|c|c|c|c|c|c|c|}
\hline & \multicolumn{2}{|c|}{ Deep } & \multicolumn{2}{|c|}{ Shallow } & \multicolumn{2}{|c|}{ Control } \\
\hline & TBR & $\overline{\mathrm{TBF}}$ & TBR & $\overline{\mathrm{TBF}}$ & TBR & $\overline{\mathrm{TBF}}$ \\
\hline Young adults & $\begin{array}{c}48.5 \\
(4.4)\end{array}$ & $\begin{array}{l}30.0 \\
(2.9)\end{array}$ & $\begin{array}{l}50.0 \\
(4.6)\end{array}$ & $\begin{array}{l}14.3 \\
(1.8)\end{array}$ & $\begin{array}{l}66.4 \\
(4.3)\end{array}$ & $\begin{array}{l}12.1 \\
(1.8)\end{array}$ \\
\hline Old adults & $\begin{array}{l}26.4 \\
(2.8)\end{array}$ & $\begin{array}{l}13.6 \\
(2.7)\end{array}$ & $\begin{array}{l}25.0 \\
(4.9)\end{array}$ & $\begin{array}{c}9.3 \\
(1.8)\end{array}$ & $\begin{array}{l}30.7 \\
(3.4)\end{array}$ & $\begin{array}{l}10.0 \\
(1.9)\end{array}$ \\
\hline
\end{tabular}

Note. Numbers in parentheses are standard errors.

\section{RESULTS}

The mean percentages of TBR and TBF words recalled, according age group, word type, and level of processing is presented in Table 1. A 2 (Age) $\times 2$ (Word Type: TBR vs TBF) $\times 3$ (Processing: Deep vs Shallow vs Control) ANOVA showed a significant main effect of Age, $F(1,54)=67.48, M S E=139.881, p<.0001$ and of Word Type, $F(1,54)=257.21, M S E=80.735, p<.0001$, indicating that young adults recalled more words than old adults and that participants recalled more TBR than TBF words. The main effect of Processing was not significant, $F(2,54)=2.47$, nor was the Processing $\times$ Age interaction, $F(2,54)=0.40$. The interaction between Processing and Word Type was however significant, $F(2,54)=14.73, M S E=$ $80.735, p<.0001$. Separate one way ANOVAs, carried out to assess how the level of processing affected recall of TBR and TBF words, indicated that recall of TBR words was equivalent across the three conditions, while more TBF words were recalled by participants who evaluated the pleasantness of each words compared to participants who counted the number of letter in a word or did not receive any particular processing instruction. The interaction between Age and Word Type was also significant, $F(1,54)=36.28, M S E=80.735, p<.0001$, and indicated that the difference between recall of TBR and TBF words was larger for young than for old adults. This last interaction was however modified by a significant three-way interaction between Age, Word Type, and Level of Processing, $F(2,54)=6.01, M S E=$ $80.735, p<.005$. This is the effect of central importance in this experiment. Separate 2 (Age) $\times 2$ (Word Type: TBR vs TBF) ANOVAs, performed on the recall scores for each processing level, indicated significant Age $\times$ Word Type interactions in the shallow processing condition, $F(1,18)=9.33, M S E=107,143, p<.01$, and in the control condition, $F(1,18)=37.30, M S E=75.539, p<.0001$, but not in the deep processing condition, $F(1,18)=1.37$. Follow-up analyses indicated that in both the shallow processing and control conditions, young adults recalled more TBR words than old adults but the two age groups recalled an equivalent percentage of TBF words. This led to larger directed forgetting effect in young compared with old adults. On the other hand, young adults in the deep processing condition recalled overall more TBR and TBF words than old adults but the interaction between the Age and Word Type was not significant, indicating equivalent directed forgetting effects in the two age groups.

\section{DISCUSSION}

The results of this experiment indicated that, overall, young adults recalled more words than old adults did. This result is in line with the extensive gerontology litera- 
ture indicating episodic memory as one aspect of cognition particularly affected by aging (e.g., Light, 1991). More importantly, results showed that the instruction to process deeply both TBR and TBF words before the occurrence of a cue led to equivalent directed forgetting effects in young and old adults. These results, together with the recent findings of age-related equivalence in the directed forgetting effects obtained using the list cueing method (Gamboz, 2000; Moulin, Macrae, \& North, 2000, Experiment 1), strengthen the hypothesis that the early findings of smaller directed forgetting effect in old than in young adults, obtained using the standard item-byitem cueing method (Zacks et al., 1996), are likely to reflect larger age-related differences in recall of words processed extensively compared to recall of words processed only superficially (due to the age-related episodic memory deficit), rather than an age-related inhibitory deficit, as suggested by Zacks et al. (1996).

The above conclusion may, however, be taken with caution because the present experiment contains two important biasing factors: the small sample size (only 10 young and old participants in each of the three experimental conditions) and the unchanged performance of the elderly across processing conditions. As indicated in Table 1, old adults recalled an equivalent percentage of TBF words in the deep, shallow, and control conditions, while young adults recalled more TBF words in the deep processing condition than in the control and shallow processing conditions. This observation was confirmed by separate ANOVAs performed on the proportion of TBF words recalled by the two age groups in the different processing conditions. The equivalent recall of TBF words of old adults across processing conditions seems to indicate that the elderly in the deep processing condition failed to process extensively the words in the study lists before the occurrence of a cue, despite the requirement to judge their pleasantness, or, alternatively they benefited from the deep orienting task at study to a smaller extent than young adults. Then, the occurrence, in the deep processing condition, of a nonsignificant interaction between Age and Word Type may simply reflect younger adults enhanced recall of TBF word, rather than indicating similar directed forgetting performance in the two age groups. It is therefore recommendable for future research to replicate the present experiment with a larger sample of participants and to use a deep orienting task more effective in increasing older adult's memory performance.

\section{REFERENCES}

Basden, B. H., \& Basden, D. R. (1996). Directed forgetting: Further comparisons of the item and list methods. Memory, 4, 633-653.

Basden, B. H., Basden, D. R., \& Gargano, G. J. (1993). Directed forgetting in implicit and explicit memory tests: A comparison of methods. Journal of Experimental Psychology: Learning, Memory and Cognition, 19, 603-616.

Erber, T. J., Herman, T. G., \& Botwinick, J. (1980). Age differences in memory as a function of depth of processing. Experimental Aging Research, 6, 341-348.

Gamboz, N. (2000). Evaluation of inhibitory processes in cognitive aging. Ph.D. dissertation, University of Essex, UK.

Golding, J. M., Long, D. L., \& MacLeod, C. M. (1994). You can’t always forget what you want: Directed forgetting of related words. Journal of Memory and Language, 33, 493-510.

Hasher, L., \& Zacks, R. T. (1988). Working memory, comprehension, and aging: A review and a new view. In G. H. Bower (Ed.), The psychology of learning and motivation (Vol. 22, pp. 193-225). San Diego: Academic Press.

Kucera, H., \& Francis, W. N. (1967). Computational analysis of present-day American English. Providence: Brown University Press.

Light, L. L. (1991). Memory and aging: Four hypotheses in search for data. Annual Review of Psychology, 42, 333-376. 
Moulin, C. J. A., Macrae, C. N., \& North, A. S. (2000). When it is good to forget: Memory inhibition in aging. Paper presented at the 2000 British Psychological Society-Cognitive Psychology Section, Essex, September 2000.

Nelson, H. E., \& O’Connell, R. E. (1978). Dementia: The estimation of premorbid intelligence levels using the new adult reading test. Cortex, 14, 234-244.

Zacks, R. T., \& Hasher, L. (1994). Directed ignoring: Inhibitory regulation of working memory. In D. Zacks, R. T. Radvansky, G., \& Hasher, L. (1996). Studies of directed forgetting in old adults. Journal of Experimental Psychology: Learning, Memory and Cognition, 22, 143-156.

Zacks, R. T., Radvansky, G., \& Hasher, L. (1996). Studies of directed forgetting in old adults. Journal of Experimental Psychology: Learning, Memory and Cognition, 22, 143-156.

This is doi:10.1006/brcg.2001.1379.

\section{Text Structure and Content Modulate the Recall of Patients with Dementia of the Alzheimer's Type}

\section{Marie-Christine Gély-Nargeot,* Bernadette Ska, $\uparrow+$ and Jacques Touchon§,đI}

*Laboratoire de Psychologie Expérimentale et Cognitive, Université Montpellier III; †Faculté de médecine, Université de Montréal; $\neq$ Centre de recherche, Institut universitaire de gériatrie de Montréal; §Faculté de médecine, Université Montpellier I; and IIUnité de neurologie comportementale, Hopital Gui de Chauliac, Montpellier

Two descriptive and two narrative texts were constructed. The basic forms of each type of text comprised 27 micropropositions, while the detailed forms incorporated an additional 24 micropropositions. Forty DAT patients and 14 control subjects were asked to read and recall the 4 texts and the total number of micropropositions recalled was recorded. Recall performance among DATs was always inferior to that of controls. For both groups, the narrative texts yielded superior recall than the descriptive texts, while the detailed text forms elicited inferior recall than the basic forms. However, the addition of details to the narrative text increased the recall of the basic propositions of DATs, bringing it to similar levels as controls. Results are discussed with reference to the influence of text structure and the situation model on text recall. (๑) 2002 Elsevier Science (USA)

\section{INTRODUCTION}

In the past decades, many studies have focused on the relationship between text type and recall in normal aging. Based on models of text comprehension inspired by Kintsch and colleagues (i.e., Kintsch, 1974, 1988; Kintsch \& van Dijk, 1978; van Dijk \& Kintsch, 1983; Ericsson \& Kintsch, 1995), these studies have referred to text components in terms of the superstructure and the situation model. The superstructure corresponds to the structure of a text, defines its type, and guides its mental representation. The superstructures or text types in the present study are narratives and descriptions. The situation model is the result of the processing and the combination of new (present in the text) and old (garnered from the reader's knowledge) information. It includes the goal and the emotional status of the characters, as well as temporal, spatial, and other characteristics of the setting.

With regard to the type of text, these studies have shown that normal aged subjects are as sensitive as younger subjects to the text structure. In comparison to descriptive or expository texts, narratives are recalled better (Adams, 1991; Hartley, 1986; Luszcz, 1993; Syssau \& Brouillet, 1996) and read more slowly (Harris, Rogers, \& Qualls, 1998). Narratives may be better recalled because their content can be reorga- 
nized in terms of a story schema, whereas descriptions simply correspond to a list of information without a predefined structure. Consequently, the load on episodic memory is much greater for descriptions than it is for narratives.

On the other hand, there are differences between younger and older adults in the number and type of information recalled. While older subjects recall as many principal ideas or macropropositions as younger subjects, they recall fewer details or subordinated micropropositions (Adams, Smith, Nyquist, \& Perlmutter, 1997). This fact depends on two major differences between younger and older adults; older adults are less efficient in episodic memory tasks (Craik, 1986; Foisy, 1995) and their processing style is more interpretive and integrative (Adams et al., 1997).

The situation model is informed by the fact that recall by older subjects is improved when the text is enriched with details about the characters or the setting, even though this addition lengthens the text. Indeed, older subjects demonstrate better recall of descriptions or narratives when emotional details are added (Syssau \& Brouillet, 1996) or when the protagonist failed to reach his goal (Radvansky \& Curiel, 1998).

The effect of dementia of the Alzheimer's type (DAT) on text recall has not been extensively researched. Some studies conclude that DAT patients recall less content than controls (i.e., Chapman, White, \& Storandt, 1997) and that they make false positives in comprehension tasks (i.e., Duchek, Balota, \& Thessing, 1998; Johnson \& Smith, 1998). These results are consistent with the view that DAT patients are impaired in working (Bickel, Pantel, Eysenbach, \& Schroder, 2000), episodic, and semantic memory (Salmon, Butters, \& Chan, 1999). However, the support provided by content familiarity and sequential organization improve the DAT patients recall (Johnson \& Smith, 1998).

The purpose of the present research was to study the effect of text type (descriptions and narratives) and content (with or without added details) on the recall performance of DAT patients. Given the known effects of text type and content on the one hand, and the memory impairment of DAT patients on the other hand, we hypothesized that narratives would be better recalled than descriptions, and that the addition of relevant details would improve recall performance for both DAT and control subjects. Finally, we assumed that the recall of DAT patients would be less accurate than that of controls.

\section{METHODS}

\section{Subjects}

Subjects were 14 patients diagnosed as having "probable" DAT according to NINCDS-ADRDA (Mc Khann et al., 1984) and DSM III $\mathrm{R}_{4}$ criteria. Screening for other causes of dementia or other concomitant diseases comprised a detailed medical history, neurological and physical examination, brain imaging, and appropriate laboratory tests. Patients with a premorbid history of psychiatric or neurological illness and those with alcohol and/or drug abuse were excluded. A minimal score of 4 was required on the Hachinski modified scale. Another inclusion criterion is the presence of a mild to moderate cognitive impairment: MMSE score $>15$ (score ranged from 16 to 27 ), and GDS $<$ degrees $3-4$. The patients ( 8 men/6 women) had an average age of 67 years (range 54-75), their mean educational level was 11 years (range 816), the length of illness was approximately 26 months (range 18-60) at time of the testing and all of them lived in their home. These patients were matched with 14 healthy elderly volunteers for age, sex, and educational levels. An age difference less than 6 months was required. Control subjects lived at home and neither complained of nor demonstrated affective or cognitive disorders (MMS > 28). No statistical differences appeared for the demographic characteristics between the groups. 
Task

Subjects were asked to listen to and then freely recall four texts: two descriptions (a sitting room and a public garden) and two narratives (a story of a dog and a story of an old man). The texts were presented in two forms; with or without extra details. The length of the texts without extra details, one narrative and one description, was equivalent (62 to 68 words). They comprise 5 macropropositions and 27 micropropositions. For the other two texts, 24 details were added increasing the number of micropropositions to 51; their length was 107 and 123 words. The substantives' imagery level is high (valence from 4 to 5, Hogenraad \& Orianne, 1983). The details consisted of qualifying words or relative clauses.

\section{Scoring}

One point was given for each correctly recalled information (a maximum of 27 for the basic micropropositions in all texts and a maximum of 24 for the added micropropositions in the two texts with details).

\section{RESULTS}

Percent of correct recall is shown in Fig. 1. Mean scores of DATs are always below those of controls $(F(1,26)=44.16 ; p<.001)$. However, control subjects only recalled $65 \%$ or less of the micropropositions contained in the texts. Both groups demonstrated inferior recall for descriptions compared to narratives $(F(1,26)=$ 51.26; $p<.001)$. Although all subjects demonstrated higher recall for texts with details compared to texts without details, this difference is not significant $(F(1,26)=$ 0.02 ; NS). There are no significant interactions between group (DTA vs Controls) and structure (Narrative vs Description) $(F(2,52)=0.002$, NS) and between group (DAT vs C) and detail (with vs without) $(F(2,52)=0.66$, NS). However, there is a trend toward a significant interaction between group and detail $(F(2,52)=3,72$; $p=.059)$.

A second analysis was performed taking only into account the basic 27 micropropositions of each text type. Percent of correct recall is shown in Fig. 2. The effect of added details on the recall of the basic micropropositions is different for DATs and controls. Addition of details to the descriptive text decreases the recall of both DAT patients and control subjects. However, the addition of details to the narrative

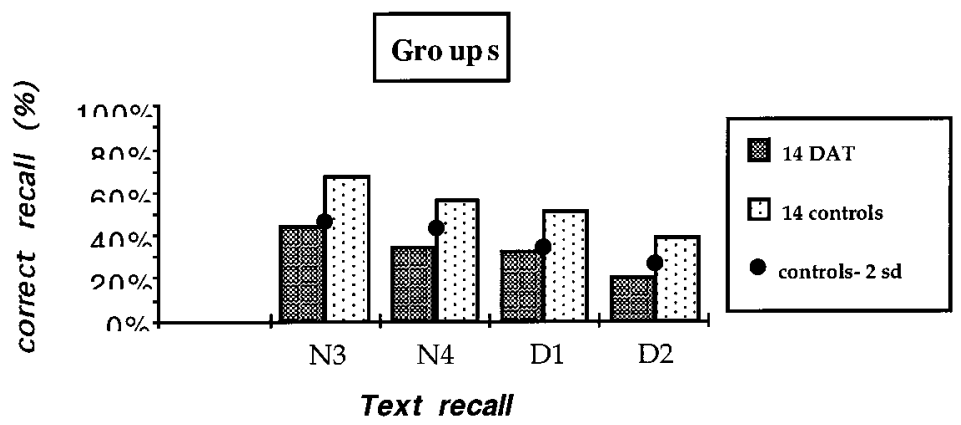

FIG. 1. Correct recall (\%) of the different texts by DAT and control subjects: D1: description without details; D2: description with details; N3: narrative without details; N4: narrative with details. 


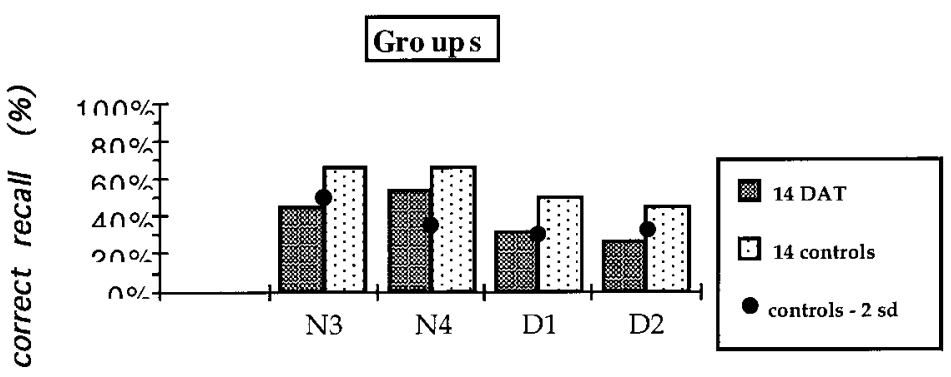

Recall of 27 micropropositions

FIG. 2. Correct recall (\%) of the 27 micropropositions by DAT and control subjects: D1: description without details; D2: description with details; N3: narrative without details; N4: narrative with details.

text increased the recall performance of DATs, bringing it to similar levels as controls.

\section{DISCUSSION}

Control subjects recalled more micropropositions than DATs. These results were expected and are in agreement with the memory impairment of DAT patients.

The text type also played the expected effect as both groups recalled fewer micropropositions in the descriptive texts than in the narrative texts. The memory load is weaker for the narratives because this type of text is more organized, more coherent, and follows a sequential progression. On the other hand, the descriptions correspond to a list of independent propositions without logical relation that only have in common the location of the setting. Consequently, any superstructure cannot support this list of micropropositions. This fact is even more penalizing for the DAT subjects.

Subjects recalled less information in the texts with details than the texts without details when global scores were analyzed. The addition of details lengthens the text and complicates the propositions. These facts increase the attentional control in order to select and process the pertinent information for the construction of a global meaning. Moreover, the material to be memorized is greater and may overlap with working memory capacities. However, when the principal propositions were considered separately from the details, the picture looks different. The principal propositions of the texts with details are as well recalled as those of the texts without details. The information conveyed by the details is omitted in the recall, showing that the subjects are able to choose between principal and secondary concepts. Thus, the added details do not interfere with higher level processing of information. Moreover, for DAT patients, details added in narratives have a positive effect, while those added in the descriptions worsen their performance compared to the control subjects. The narratives with details seem to bring many helpful factors together and DAT patients take advantage of this condition. On the other hand, details added to the descriptions have an inverse effect and they increase the load on information processing and working memory. Syssau and Brouillet (1996) obtained the inverse pattern. The difference between the texts was the manipulation of the title, which was neutral or emotional. The recall of the DAT subjects was better for the description than for the narrative when an affective connotation was added. In our study, the qualification conveyed by the details was not emotional.

In conclusion, this study shows that DAT and normal aged subjects are sensitive to text structure and it is possible to enhance the recall when the text contains informa- 
tion that allows for the elaboration of a situation model. However, the type of details is crucial and their addition may be counterproductive.

\section{REFERENCES}

Adams, C. (1991). Qualitative age differences in memory for text: A life-span developmental perspective. Psychology and Aging, 6(3), 323-336.

Adams, C., Smith, M. C., Nyquist, L., \& Perlmutter, M. (1997). Adult age group differences in recall for the literal and interpretive meanings of narrative text. Journal of Gerontology, Psychological Sciences, 52B, 187-195.

Bickel, C., Pantel, J., Eysenbach, K., \& Schroder, J. (2000). Syntactic comprehension deficits in Alzheimer's disease. Brain and Language, 71, 432-48.

Chapman, L. L., White, D. A., \& Storandt, M. (1997). Prose recall in dementia—A comparison of delay intervals. Archives of Neurology, 54, 1501-1504.

Craik, F. (1986). A functional account of age differences in memory. In F. Klix \& H. Hagendorf (Eds.), Human memory and cognitive capabilities: Mechanisms and performances (pp. 409-422). NorthHolland: Elsevier.

Duchek, J. M., Balota, D. A., \& Thessing, V. C. (1998). Inhibition of visual and conceptual information during reading in healthy aging and Alzheimer's disease. Aging Neuropsychology and Cognition, 5(3), 169-181.

Ericsson, K. A., \& Kintsch W. (1995). Long-term working memory [Review]. Psychological Review, 102(2), 211-245.

Foisy, P. (1995). Variations in age-related deficits among episodic memory tasks: An archival study. Canadian Journal of Aging, 14, 687-696.

Harris, J. L., Rogers, W. A., \& Qualls, C. D. (1998). Written language comprehension in younger and older adults. Journal of Speech Language and Hearing Research, 41(3), 603-617.

Hartley, J. T. (1986). Reader and text variables as determinants of discourse memory in adulthood. Psychology and Aging, 1, 150-158.

Hogenraad, R., \& Orianne, E. (1983). “A penny for your thoughts”: Imagery value and periodicity of interior monologue. Journal of Mental Imagery, 7, 51-61

Johnson, D. L., \& Smith, S. D. (1998). Effects of familiarity and temporal organization on memory for event schemas in aged and Alzheimer subjects-Implications for clinical management. Alzheimer Disease and Associated Disorders, 12, 18-25.

Kintsch, W. (1974). The representation in meaning in memory. Hillsdale, NJ: Erlbaum.

Kintsch, W. (1988). The role of knowledge in discourse comprehension: A construction-integration model. Psychological Review, 95(2).

Kintsch, W., \& van Dijk, T. A. (1978). Toward a model of text comprehension and production. Psychological Review, 85, 363-394.

Luszcz, M. A. (1993). Orienting tasks as moderators of narrative and expository text recall in adulthood. Psychology and Aging, 8, 56-58.

McKhann, G., Drachman, D., Folstein, M., Katzman, R., Price, D., \& Standlan, E. M. (1984). Clinical diagnosis of Alzheimer's disease: Report of the NINCDS-ADRDA work group under the auspices of the Department of Health and human Services Task Force on Alzheimer's disease. Neurology, 34, 939-944.

Radvansky, G. A., \& Curiel, J. M. (1998). Narrative comprehension and aging. The fate of completed goal information. Psychology and Aging, 13, 69-79.

Salmon, D. P., Butters, N., \& Chan, A. S. (1999). The deterioration of semantic memory in Alzheimer's disease. Canadian Journal of Experimental Psychology, 53, 108-17.

Syssau, A., \& Brouillet, D. (1996). Rôle de la valeur affective et de la nature du texte dans la récupération du souvenir chez les sujets âgés. Annee Psychologique, 96, 85-112.

van Dijk, T. A., \& Kintsch, W. (1983). Strategies of discourse comprehension. New York: Academic Press.

This is doi:10.1006/brcg.2001.1380. 


\title{
Learning to Divide the Labor between Syntax and Semantics: A Connectionist Account of Deficits in Light and Heavy Verb Production
}

\author{
Jean Gordon and Gary Dell
}

Beckman Institute, University of Illinois at Urbana-Champaign

\begin{abstract}
In aphasic subjects who demonstrate difficulty producing verbs, a double dissociation has been observed between light verbs (e.g., GO) and heavy verbs (e.g., FLY). A simple connectionist model of sentence production, lesioned to simulate agrammatic- and anomic-like deficits, suggests that this dissociation arises from light verbs learning to rely more on syntactic cues and heavy verbs learning to rely more on semantic cues. Systematic manipulations of the variables which distinguish light and heavy verbs reveal that it is primarily the greater frequency of occurrence of light verbs, and the fact that they are specified by fewer semantic features, which cause them to depend more on syntactic information. Implications are discussed for models of lexical access in both normal and aphasic populations. (๑) 2002 Elsevier Science (USA)
\end{abstract}

\section{INTRODUCTION}

Since the earliest descriptions of aphasia, neurolinguists have focused on dichotomous patterns of language behavior. One such example is the comparison of agrammatism and anomia. Whereas agrammatics have been observed to have particular difficulty producing grammatical function words (e.g., determiners, prepositions, pronouns) relative to content words (e.g., nouns, verbs, adjectives), anomic aphasics demonstrate the opposite pattern (Goodglass \& Kaplan, 1983). More specific dissociations have been noted within the category of content words. Several studies have illustrated that some aphasic patients have more difficulty producing nouns than verbs, while others have relatively more difficulty producing verbs (e.g., Berndt, Mitchum, Haendiges, \& Sandson, 1997a; Damasio \& Tranel, 1993; Hillis \& Caramazza, 1995; Williams \& Canter, 1982; Williams \& Canter, 1987; Zingeser \& Berndt, 1990).

Moreover, recent studies have shown that, in patients with verb impairments, semantically light verbs such as "go" appear to dissociate from heavy verbs such as "fly", (Berndt, Haendiges, Mitchum, \& Sandson, 1997b; Breedin, Saffran, \& Schwartz, 1998; Kohn, Lorch, \& Pearson, 1989). Some aphasic patients seem to rely on light verbs in spontaneous speech tasks, as a default strategy in the face of failure to retrieve a specific verb (Berndt et al., 1997b; Kohn et al., 1989), but others produce more heavy than light verbs (Breedin et al., 1998). In a more constrained task involving delayed repetition, some subjects tended to substitute lighter for heavier verbs, while others substituted heavier for lighter verbs (Breedin et al., 1998). The authors hypothesized that the greater complexity of heavy verbs may make them more difficult to retrieve for some patients, while their relative semantic richness may make them more resistant to disruption in other patients.

Such double dissociations have been interpreted as strong evidence for the independence of representational stores or processing modules. However, whereas the distinctions between content and function words, and between nouns and verbs, are independently motivated on linguistic grounds, it is not clear why heavy and light verbs should dissociate. They belong to the same syntactic category, and occupy the same semantic spaces, but differ quantitatively along several dimensions: light verbs have fewer semantic features, are also less constrained by semantic context, and occur more frequently than heavy verbs.

An alternate explanation of this double dissociation emerges from connectionist 
approaches to neuropsychology. Connectionist models can produce nontransparent dissociations because their learning assumptions create a 'division of labor" among representational elements to predict other elements (see Plaut, 1995; Plaut, McClelland, Seidenberg, \& Patterson, 1996). In one model (Joanisse \& Seidenberg, 1999), regular past tense forms (e.g., "walked") came to be generated largely via the phonological form of the verb root (particularly the final consonant). Irregular forms (e.g., "ran') were signaled more by the semantic features of the root. Importantly, both phonological and semantic features were required to generate the output, although their relative contributions varied with the kind of verb.

The current study uses a similar approach to the observed dissociation between light and heavy verb production in aphasia. It is hypothesized that there is a continuum of dependence of lexical production on syntax and semantics, with words like determiners at one end (almost purely syntactic), concrete nouns and heavy verbs at the other (almost purely semantic), and light verbs intermediate, and that it is this trade-off of syntactic and semantic cues which results in the light/heavy verb dissociation.

\section{METHODS}

A connectionist model of sentence production was constructed from a two-layered nonlinear feed-forward network (see Fig. 1). The input layer consisted of syntactic and semantic features; the output layer consisted of the lexical items which formed the sentences, including both light and heavy verbs. The network was set up to approximate the relative properties of light and heavy verbs in natural language samples: light verbs were represented in target sentences more frequently than heavy verbs and had fewer contextual constraints (i.e., they co-occurred with more of the model's nouns). The two light verbs also had fewer semantic features than the heavy verbs, each being specified by a subset of the heavy verb features. Thus, GO was specified by the feature motion, FLY was specified by the features motion and air, and SKIP was specified by the features motion and playful. All input nodes had potential connections to all output nodes. The weights on these connections were set by training the model, using the delta rule, to map semantic messages onto grammatical sequences of words (see Fig. 2 for an example).

After training, the probability of production of each intended target item was calculated by a stochastic choice rule (McClelland \& Rumelhart, 1981). Several different simulations were run, modifying the original model to systematically manipulate the variables which differentiate light from heavy verbs (frequency of occurrence, range of distribution, and number of features). For each version of the model, once the " "normal" model was sufficiently trained, it was lesioned to simulate either a syntactic (agrammatic-like) deficit or a semantic (anomic-like) deficit. Syntactic lesions involved setting all connection weights from the syntactic input features to zero; semantic lesions were simulated by severing connections from all semantic input features.

\section{RESULTS}

\section{Normal Models}

In the unlesioned model, the determiner THE (which appeared in every sentence) was extremely well learned, showing a likelihood of production of almost $100 \%$. The four nouns, which were evenly distributed throughout the sentences, were equally 


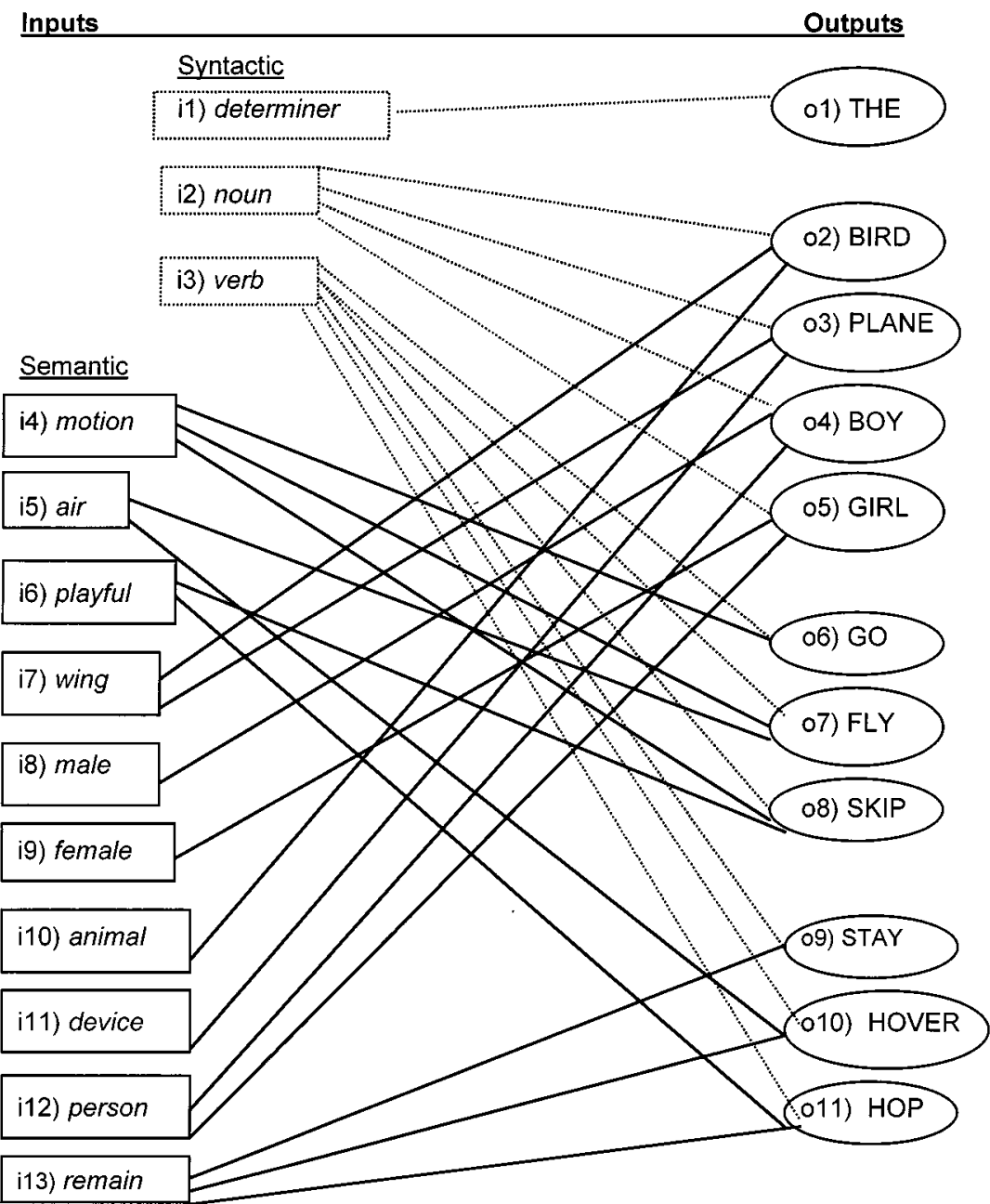

FIG. 1. Input and output layers. Note that lines do not represent learned connections (all inputs potentially connect to all outputs); rather, lines indicate intended mappings from syntactic features (dotted) and semantic features (solid) to lexical items.

well learned, each with a $99 \%$ chance of production. The light verbs, however, were learned more quickly and more reliably than heavy verbs. Light verbs showed a mean probability of production of $95 \%$, compared to $83 \%$ for heavy verbs, indicating that heavy verbs were more prone to substitution. For the noun slot in each sentence, the next most likely item to be produced was a related noun (e.g., PLANE for BIRD), and in the verb slot, the next most likely item was a related verb (e.g., GO for FLY). Thus, in the unlikely event of an error, syntactic category constraints, as observed in normal error studies (e.g., Garrett, 1992), were preserved.

\begin{tabular}{ll} 
Input & Output \\
\hline determiner, wing, animal, motion, air & THE \\
noun, wing, animal, motion, air & BIRD \\
verb, wing, animal, motion, air & FLY
\end{tabular}

FIG. 2. Input consisted of sets of syntactic and semantic features defining simple intransitive sentences. Desired output consisted of the lexical items appropriate to each sentence. 
The most obvious source of the light verbs' advantage is their relatively high frequency of occurrence. To assess this possibility, the training corpus was altered to match the frequencies of heavy and light verbs, while preserving their different distributions. In the resulting output, light verbs were less likely to be produced when targeted (mean $p=81 \%$ ) than were heavy verbs (mean $p=94 \%$ ). This reverse effect can be attributed to differences in distribution. When both frequency and range of distribution were equalized for light and heavy verbs, their production probabilities became almost identical (90\%). Finally, the original model (with unequal frequencies and distributions) was modified to match the number of semantic features specifying light and heavy verbs. The resulting output activations illustrated that the advantage for light verbs (mean $p=97 \%$ ) over heavy verbs (mean $p=93 \%$ ) was maintained, though it was not as great as in the original model.

\section{Lesioned Models}

In the syntactically lesioned model, all syntactic word-order cues were lost, so the output activation pattern was the same for each of the three slots in a given sentence. The most likely item to be produced was the target noun, at a mean probability of $54 \%$ across target sentences, followed by heavy verbs (mean $p=34 \%$ ), then light verbs (mean $p=18 \%$ ). The determiner had a consistently low activation level (mean $p=11 \%$ ). Thus, a typical sentence output would be "Bird . . . bird,', or perhaps "'Bird, flies," a pattern typical of agrammatism. The generally low production probabilities also increase the likelihood that no lexical item would be produced at all.

In the semantically lesioned model, the output activation pattern was different for each node in the sentence, but because all semantic information was lost, the same three patterns occurred for each target sentence. The determiner retained a high likelihood of production $(99.6 \%)$. The four nouns were all highly activated, but to virtually the same degree, giving each about a $25 \%$ probability of production, regardless of the target. Light verbs had a much higher likelihood of production (mean $p=38 \%$ ) than heavy verbs (mean $p=6 \%$ ). Thus, the resulting output would take the form of a semantically empty sentence such as "The [randomly chosen noun] goes" (or, given a default light noun, "The thing goes"), a typically anomic response.

Similar patterns of output were shown when each version of the model was lesioned, with one exception. Regardless of the manipulations of frequency and distribution, light verbs were more disrupted than heavy verbs in the syntactically lesioned models, and heavy verbs were more disrupted than light verbs in the semantically lesioned models. When both light and heavy verbs were represented by the same number of semantic features, however, light verbs no longer showed a significantly greater degree of disruption in the syntactically lesioned model, although the difference was in the same direction.

\section{DISCUSSION}

The differential behavior of light and heavy verbs can be explained by examining the weights on syntactic and semantic connections in the trained models (see Fig. 3 ). In the original model, the heavy verbs receive some positive input from the syntactic verb node, but most of their activation comes from the semantic feature nodes. In contrast, light verbs are primarily activated by the syntactic verb node and to a much lesser extent by their semantic features. Therefore, when syntactic connections were cut, light verbs were disrupted more than heavy verbs, and when semantic connections were cut, heavy verbs were disrupted more than light verbs. 
Semantic Features

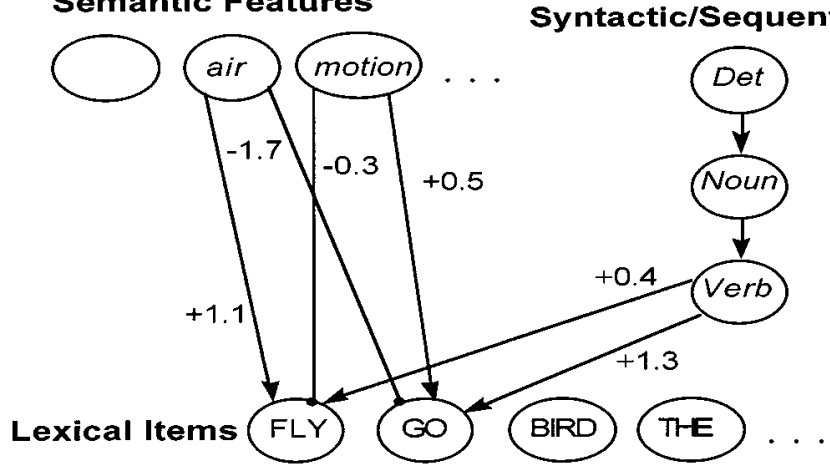

FIG. 3. Comparison of principal syntactic and semantic connection weights for one light verb (GO) and one heavy verb (FLY).

Manipulating the characteristics of light and heavy verbs in subsequent simulations revealed that frequency exerts its effect primarily in the relative connection weights from the verb node, making light verbs function to some extent as default verbs. On the other hand, the effect of distribution, manifest primarily in the semantic connections between verbs and the nouns with which they co-occur, gave a relative advantage to heavy verbs, which had more consistent noun-verb associations. The main reason, however, for the light verbs' reliance on syntax was the fact that they had fewer semantic features; adding a feature served to transfer much of responsibility for activation from the verb node to the semantic features.

Although the model is an extremely simplified characterization of lexical access in production, there are some firm conclusions that can be drawn. First, and most important, a double dissociation between heavy and light verbs can be simulated without postulating separate representations. The dissociation is most apparent in the original model, which most closely reflects reality, when light verbs are more frequent, less constrained, and specified by fewer features than heavy verbs. Their simpler semantics and wider co-occurrences with other sentence constituents make for relatively weak semantic cues, thus forcing the syntax to bear much of the responsibility for successful access. Second, given our representational and lesioning assumptions, function words pattern with light verbs and nouns with heavy verbs. Third, the syntax and semantics lesions tend to lead to underactivation and overactivation of lexical units, respectively. These characteristics of the model suggest that connectionist approaches have some promise in explaining dissociations in lexical access and their possible association with syntactic and semantic deficits.

\section{REFERENCES}

Berndt, R. S., Haendiges, A. N., Mitchum, C. C., \& Sandson, J. (1997b). Verb retrieval in aphasia: 2. Relationship to sentence processing. Brain and Language, 56, 107-137.

Berndt, R. S., Mitchum, C. C., Haendiges, A. N., \& Sandson, J. (1997a). Verb retrieval in aphasia: 1. Characterizing single word impairments. Brain and Language, 56, 68-106.

Breedin, S. D., Saffran, E. M., \& Schwartz, M. F. (1998). Semantic factors in verb retrieval: An effect of complexity. Brain and Language, 63, 1-31.

Damasio, A. R., \& Tranel, D. (1993). Nouns and verbs are retrieved with differently distributed neural systems. Proceedings of the National Academy of Sciences USA, 90, 4957-4960.

Garrett, M. (1992). Disorders of lexical selection. Cognition, 42, 143-180.

Goodglass, H., \& Kaplan, E. (1983). The assessment of aphasia and related disorders. Philadelphia: Lea \& Febiger. 
Hillis, A. E., \& Caramazza, A. (1995). Representation of grammatical categories of words in the brain. Journal of Cognitive Neuroscience, 7(3), 396-407.

Joanisse, M. F., \& Seidenberg, M. S. (1999). Impairments in verb morphology after brain injury: A connectionist model. Proceedings of the National Academy of Sciences USA, 96, 7592-7597.

Kohn, S. E., Lorch, M. P., \& Pearson, D. M. (1989). Verb finding in aphasia. Cortex, 25, 57-69.

McClelland, J. L., \& Rumelhart, D. E. (1981). An interactive activation model of context effects in letter perception: Part 1. An account of basic findings. Psychological Review, 88, 375-407.

Plaut, D. (1995). Double dissociations without modularity: Evidence from connectionist neuropsychology. Journal of Clinical and Experimental Neuropsychology, 17(2), 291-321.

Plaut, D. C., McClelland, J. L., Seidenberg, M. S., \& Patterson, K. (1996). Understanding normal and impaired word reading: Computational principles in quasi-regular domains. Psychological Review, 103(1), 56-115.

Williams, S. E., \& Canter, G. J. (1982). The influence of situational context on naming performance in aphasic syndromes. Brain and Language, 17, 92-106.

Williams, S. E., \& Canter, G. J. (1987). Action-naming performance in four syndromes of aphasia. Brain and Language, 32, 124-136.

Zingeser, L. B., \& Berndt, R. S. (1990). Retrieval of nouns and verbs in agrammatism and anomia. Brain and Language, 39(1), 14-32.

This is doi:10.1006/brcg.2001.1381.

\title{
Sentence Context Effects and the Timecourse of Lexical Ambiguity Resolution in Nonfluent Aphasia
}

\author{
Christopher M. Grindrod and Shari R. Baum
}

McGill University

In the current neurolinguistic literature, two proposals have been put forth to account for the deficit in ambiguous word processing observed in nonfluent aphasic patients. One proposal maintains that these individuals are impaired in the selective access of ambiguous word meanings, while the other argues that they are impaired in the process of contextual selection. In the present study, nonfluent aphasic patients and elderly control subjects participated in a semantic priming experiment, in which ambiguous words were presented in different biasing contexts at both a 0- and 750-ms ISI. At both ISIs, control subjects showed context-selective access, in that only contextually appropriate meanings were activated. In contrast, at the 0 ms ISI, the nonfluent aphasic patients showed activation of both meanings of the ambiguous word regardless of context. Only at the 750-ms ISI did they exhibit context-selective access. These results are consistent with the proposal that left hemisphere damage causing nonfluent aphasia results in an impairment in rapidly integrating lexical-semantic information into context. (c) 2002 Elsevier Science (USA)

\section{INTRODUCTION}

Lexical ambiguity resolution not only requires intact access to the various meanings of an ambiguous word, but also an intact ability to select which meaning is appropriate in a given context. Recent research has shown that nonfluent aphasic patients exhibit a deficit in processing ambiguous words, however no consensus on the underlying impairment has been reached. Some researchers have argued that nonfluent aphasic patients are impaired in the selective access of ambiguous word meanings (Milberg, Blumstein, \& Dworetzky, 1987; Swinney, Zurif, \& Nicol, 1989), while others have argued that they are impaired in the process of contextual selection (Hagoort, 1993; Swaab, Brown, \& Hagoort, 1998). 
Evidence for a contextual selection deficit has come from studies where different inter-stimulus intervals (ISIs) were used to assess the timecourse of ambiguous word meaning activation and selection in aphasic patients. For example, in an ERP study, Swaab et al. (1998) found that at a short ISI (100 ms), Broca's aphasic patients, in contrast to the control subjects, were unable to select the contextually appropriate meaning (i.e., the inappropriate meaning was also activated). Only at a much longer ISI $(1250 \mathrm{~ms})$ did the Broca's aphasic patients show any evidence of contextual selection. These results led the authors to conclude that Broca's aphasic patients are delayed in the process of contextual selection (i.e., in integrating lexical-semantic information into context). The present study was designed to further test this claim.

\section{METHOD}

\section{Subjects}

Two groups of subjects were tested: a nonfluent aphasic group $(n=10)$ and an elderly control group $(n=18)$. All subjects were right-handed, native speakers of English. Aphasic patients had lesions confined to the left hemisphere (LH), as documented by MRI or CT scan. Exclusionary criteria for the patients included multiple infarcts, history of drug or alcohol abuse, and history of psychiatric or neurological illness. Diagnosis of aphasia was based on results of the Boston Diagnostic Aphasia Examination (BDAE; Goodglass \& Kaplan, 1983). All control subjects were matched as closely as possible to the patients in terms of age and education.

\section{Materials}

Experimental stimuli consisted of 30 homonyms with two equally frequent meanings. Equibiased homonyms were used in an attempt to decrease the likelihood of frequency-driven meaning selection, so that the effects of context on lexical ambiguity resolution could be isolated. For each homonym, three sentence contexts were constructed: a neutral (i.e., ambiguous) context, one biased toward the first meaning and another biased toward the second meaning. All experimental sentences were composed of two clauses, with the second (unbiased) clause held constant across the three contexts (e.g., he looked at the card). The first clause was manipulated in each condition to create the appropriate context (e.g., Although trying not to cheat, he looked at the card). Control sentences were constructed by replacing sentence-final homonyms with unambiguous control words (e.g., Although trying not to cheat, he looked at the test). Control words were matched for frequency and length with the homonyms. Visual targets were associates related to one of the two meanings of the homonym (e.g., birthday/poker).

\section{Experimental Design and Procedure}

The experiment was a 2 (Group: nonfluent aphasic patients and control subjects) $\times$ 3 (Context: neutral, first- and second-meaning biased) $\times 2$ (Sentence Prime Type: homonym- or control-bearing) $\times 2$ (Target Type: first or second meaning related) $\times$ 2 (ISI: 0 or $750 \mathrm{~ms}$ ) repeated measures design. The dependent variables were lexical decision latency and accuracy. Twelve lists (six per ISI) were created such that neither the sentence primes nor targets were repeated within a list. Aphasic patients were tested in six sessions of approximately $45 \mathrm{~min}$ each (three sessions per ISI). Control subjects were randomly assigned to only one ISI condition, thus they completed three sessions in total. Within each session, subjects were presented with two lists, in a 
blocked design. Order of presentation of the lists was counterbalanced across all subjects and ISI was counterbalanced across the aphasic patients. Within each ISI condition, the three sessions were separated by at least one week. For the nonfluent aphasic group, at least eight weeks elapsed before testing of the second ISI condition commenced.

Each experimental trial began with the presentation of an auditory sentence. At 0 or $750 \mathrm{~ms}$ after the offset of the sentence-final homonym or control word, a visual target was centrally displayed. Subjects made a lexical decision on the targets (using their currently dominant hand). Reaction time was recorded from the onset of the visual target until the subject responded. A practice session of 10 trials preceded each experimental session. To ensure that subjects listened to the sentences, they were told that a recall task (containing some of the experimental sentences) would be administered at the end of each session.

\section{RESULTS}

For each ISI condition, separate repeated measures ANOVAs were performed on the mean reaction times for correct responses to real word targets. Two nonfluent aphasic patients did not complete the 0-ms ISI condition and two patients did not complete the 750-ms ISI condition. Thus, the analyses reported below are based on the results of eight nonfluent aphasic patients and nine control subjects in each ISI condition.

\section{O-ms ISI Condition}

For the 0-ms ISI condition, there was a marginally significant main effect for Group $[F(1,15)=4.18, p=.06]$ and significant main effects for Prime Type $[F(1,15)=$ $7.37, p<.05]$ and Target Type $[F(1,15)=16.96, p<.001]$. A significant interaction was also found for Group $\times$ Context $\times$ Target Type $[F(2,14)=4.29, p<.05]$ and a marginally significant interaction for Context $\times$ Prime Type $[F(2,14)=3.37, p=$ .06]. A comparison of the control subjects' reaction times in the related and control conditions showed that only the contextually appropriate meanings were facilitated in both of the biased contexts. More specifically, after a context biased toward the first meaning of the ambiguous word, only targets related to that meaning were facilitated relative to the control condition (1069 vs $1098 \mathrm{~ms}$ ), whereas after a context biased toward the second meaning, only targets related to the second meaning were facilitated relative to the control condition (1040 vs $1072 \mathrm{~ms}$ ). In contrast, after a neutral (i.e., ambiguous) context, where both meanings were expected to show facilitation, only targets related to the first (potentially more frequent) meaning were facilitated relative to the control condition (1083 vs $1113 \mathrm{~ms}$ ). Thus, the control subjects produced a pattern of results consistent with context-dependent access. In contrast to the results obtained for the control subjects, a comparison of the nonfluent aphasic patients' reaction times in the related and control conditions revealed a very different pattern of priming. After a neutral context, targets related to both meanings of the ambiguous word were facilitated relative to the control conditions (First meaning: 1277 vs 1333 ms; Second meaning: 1262 vs 1324 ms). Targets related to both meanings were once again facilitated after a context biased toward the first meaning of the ambiguous word (First meaning: 1298 vs 1343 ms; Second meaning: 1263 vs $1308 \mathrm{~ms}$ ). Moreover, after a context biased toward the second meaning, no significant effects were observed for targets related to either meaning. In sum, results for the 
nonfluent aphasic patients demonstrate that activation of ambiguous word meanings at the 0-ms ISI is not dependent on prior contextual bias.

\section{0-ms ISI Condition}

For the 750-ms ISI condition, there was a significant main effect for Group $[F(1$, $15)=7.69, p<.01]$. There was also a significant interaction for Group $\times$ Context $\times$ Prime Type $[F(2,14)=5.11, p<.05]$. In addition, marginally significant interactions were found for Group $\times$ Prime Type $[F(1,15)=3.35, p=.09]$ and for Context $\times$ Prime Type $\times$ Target Type $[F(2,14)=3.36, p=.06]$. For the control subjects, a comparison of reaction times in the related and control conditions paralleled the effects seen in the 0-ms ISI condition, with one exception: Somewhat surprisingly, the pattern of facilitation was reversed in the neutral context, such that priming was only observed for targets related to the second meaning of the ambiguous word (983 vs $998 \mathrm{~ms}$ ). Moreover, the effects observed for the nonfluent aphasic patients were more in line with those of the control subjects. After a neutral context, only targets related to the second meaning were facilitated relative to the control condition (1203 vs 1224 $\mathrm{ms}$ ), whereas after a context biased toward the first meaning, only targets related to that meaning were facilitated (1220 vs $1240 \mathrm{~ms}$ ). As in the 0-ms ISI condition, no significant priming effects were produced in contexts biased toward the second meaning of the ambiguous word. Thus, for the nonfluent aphasic patients, the pattern of results obtained at the 750-ms ISI provides some evidence for context-dependent access.

\section{DISCUSSION}

The present results are consistent with the hypothesis that nonfluent aphasic patients have a deficit in integrating the appropriate meaning of an ambiguous word into context (Hagoort, 1993; Swaab et al., 1998). They also argue against the hypothesis that nonfluent aphasic patients do not access both meanings of an ambiguous word or that they only have access to the dominant meaning (Milberg et al., 1987; Swinney et al., 1989). For these patients, initial meaning activation proceeds independent of context (i.e., initial access is exhaustive). Only at a later point in the comprehension process does context begin to play a role (at least by $750 \mathrm{~ms}$ ). In contrast, non-braindamaged control subjects are able to use context very early on in the processing of an ambiguous word. If one meaning is constrained by the sentence context, only this meaning will be activated. In sum, LH damage causing nonfluent aphasia disrupts lexical ambiguity resolution to the extent that it produces a delay in the contextual selection process.

\section{REFERENCES}

Goodglass, H., \& Kaplan, E. (1983). The assessment of aphasia and related disorders. Philadelphia: Lea and Febiger.

Hagoort, P. (1993). Impairments of lexical-semantic processing in aphasia: Evidence from the processing of lexical ambiguities. Brain and Language, 45, 189-232.

Milberg, W., Blumstein, S. E., \& Dworetzky, B. (1987). Processing of lexical ambiguities in aphasia. Brain and Language, 31, 138-150.

Swaab, T. Y., Brown, C., \& Hagoort, P. (1998). Understanding ambiguous words in sentence contexts: Electrophysiological evidence for delayed contextual selection in Broca's aphasia. Neuropsychologia, 36, 737-761. 
Swinney, D., Zurif, E., \& Nicol, J. (1989). The effects of focal brain damage on sentence processing: An examination of the neurological organization of a mental module. Journal of Cognitive Neuroscience, 1, 25-37.

This is doi:10.1006/brcg.2001.1382.

\title{
Syntactic Breakdown and Recovery of Clausal Structure in Agrammatism
}

\author{
Maria Teresa Guasti and Claudio Luzzatti
}

Department of Psychology, State University of Milano-Bicocca, Milano, Italy

We studied the recovery of clause structures in four agrammatic patients by performing a longitudinal analysis of their spontaneous production. We classified their utterances in terms of legitimacy of the syntactic structure and rate of subordination. The results show that, initially, patients omit verbs, avoid subordination, just employ present tense, and substitute finite verbs with infinitives. During the recovery they start employing other tenses and subordinate clauses and reduce the use of infinitives. Data suggest a mixed syntactic and morphological origin of the impairment. Assuming that phrasal representations are built bottom-up from an array of lexical items, we propose that syntactic structures recover stepwise, with the lower portion of the syntactic tree becoming accessible before higher portions. We claim that, despite superficial similarities between agrammatic and children's speech, e.g., use of infinitives instead of finite verbs, a unified account is not viable. (c) 2002 Elsevier Science (USA)

\section{INTRODUCTION}

Agrammatic speech is often said to be "telegraphic," since it has simplified sentence structure and displays frequent omission of functional morphemes. Recently, it has been shown that not all the functional morphemes are equally impaired and that patients' speech is at least partially constrained by the same rules that govern language in normal subjects (see Lonzi \& Luzzatti, 1993; Bastiaanse \& van Zonneveld, 1998; Grodzinsky \& Friedmann, 2000; among others). In this study, we pursue this line of research by providing a syntactic description of the spontaneous production of four agrammatic patients and by analyzing longitudinally the recovery of syntactic structures.

Agrammatic syntactic impairment has been said to resemble children's production. Children, as agrammatic patients, omit functional morphemes (articles, auxiliaries, and prepositions) and often produce infinitives instead of finite verbs, a phenomenon that is attested in early Dutch, English, French, German, and Swedish (see Wexler, 1994; Rizzi, 1994). Early infinitives are structurally constrained, since they seem to occur in main declarative clauses, but not in negative clauses, in subordinate clauses and in questions. Italian, Spanish, and Catalan speaking children constitute an exception: infinitives replacing finite verbs are very rare (Guasti, 1993; Torrens, 1995; Bottari, Cipriani, \& Chilosi, 1996). Then, the question arises as to whether children and agrammatic telegraphic speech output may have a similar account.

\section{MATERIALS AND METHODS}

\section{Subjects}

R.O. was a 43-year-old Italian employee who suffered from a cerebral abscess in the left hemisphere (LH) causing severe nonfluent language impairment that slowly 
improved to a severe Broca's aphasia with agrammatism. His spontaneous speech was repeatedly recorded in three sessions during the 10 months following the onset of the disease.

A.D. was an 18-year-old schoolgirl who suffered from the rupture of an aneurysm causing the formation of a satellite hematoma in the LE. Her spontaneous speech was severely agrammatic. It was recorded in three sessions during four months following the onset of the disease.

C.M. was a 20-year-old student of medicine who sustained a traumatic head injury. His spontaneous speech was recorded in three sessions during 15 months following the onset of the disease.

E.B. was a 17-year-old schoolboy who suffered from a left perysilvian cerebrovascular attack. His spontaneous verbal production was recorded in 6 sessions during 12 months following the onset of the disease.

\section{Speech Analysis}

The speech samples were transcribed to obtain a corpus of 1347 (O.D.), 2398 (A.D.), 4523 (C.M.), and 6121 words (E.B.). Incomprehensible and ambiguous utterances, repetitions, interjections and "yes" "no" sentences were discarded.

The corpora were analyzed for illegal omission of verbs (IOV), infinitives substituting finite verbs $(I V)$, past participles with illegal auxiliary omission $(P P)$, and subordinate clauses including a verb $(S C)$. The rate of $I O V$ was calculated by dividing the number of clauses missing a verb over the total number of clauses (with/without a verb). The rate of IV was obtained by dividing the number of infinitives substituting finite verbs by the number of infinitive plus finite verbs, while that of PP by dividing the number of past participles missing the auxiliary by the number of past participles with and without auxiliaries. Finally, the rate of SC is obtained by dividing the number of subordinate clauses (finite and infinitive) by the total number of clauses. Infinitives following modal verbs (e.g., voglio mangiare, I want to eat) were not counted as independent subordinate elements). Other typical phenomena of agrammatism (e.g., omission of articles and of prepositions) were not considered here.

\section{RESULTS}

Figure 1 shows the performance of the four patients for IOV, IV, PP, and SC in the different sessions. R.O.'s speech production is characterized all along the period investigated by a large number of IV (64\%), IOV (51\%), exclusive use of present tense, and complete absence of SC.

A.D.'s initial speech production has features similar to those described for R.O., but her output improved during the follow-up period. IV dropped from 50 to $22 \%$, IOV from 77 to $48 \%$; SC started to appear only at the third session. As for finite verbs, in the first two sessions only the present tense was used, past tense forms appeared from the third session. Finally, auxiliary omissions in compound tenses droped from 100 to $67 \%$.

In E.B., IV decrease from 30 to $2 \%$, SC increase from 7 to $34 \%$, and IOV drop from 55 to $20 \%$. Present and imperfect are used from the beginning, past tense from the second session only. In the first sessions, auxiliaries were always omitted, but during the follow-up the omission rate droped to $8 \%$. E.B. used infinitives in a variety of syntactic contexts: in positive declarative (43/49) and in negative declarative sentences (6/49) and also in subordinate clauses (4/51). Infinitives in main clauses are $49 / 387$. 


\section{R.o.}

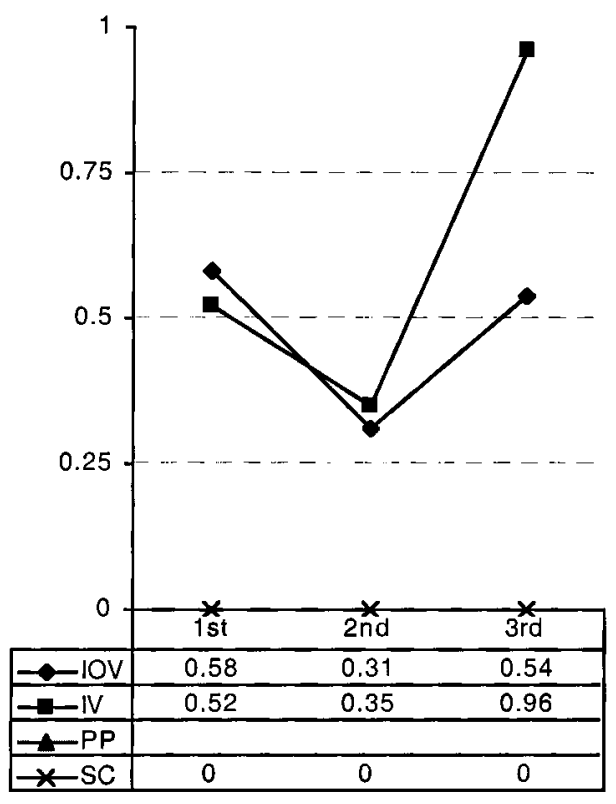

(a)

A.D.

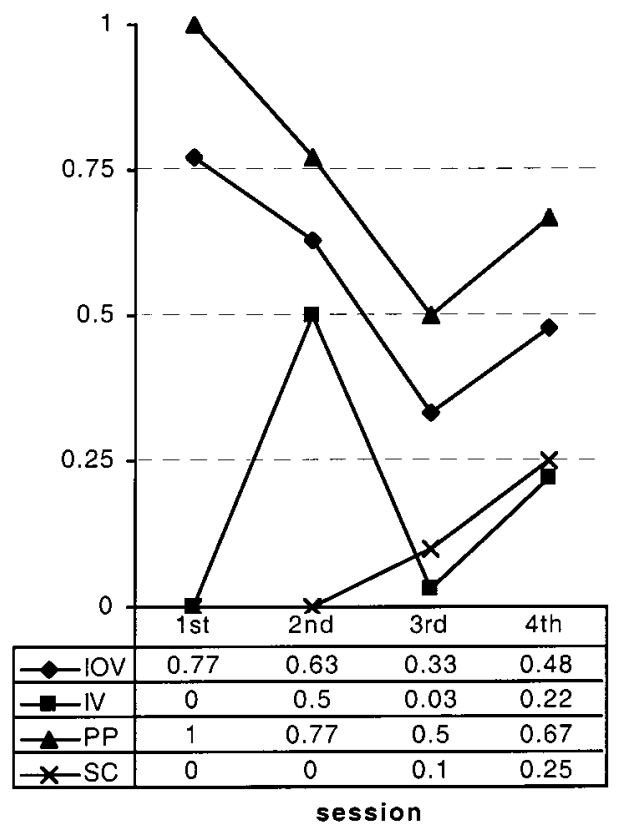

(b)

FIG. 1. (a)-(d) Patients' performance for IOV, IV, PP, and SC (IOV = illegal omission of verbs; IV = infinitives substituting finite verbs; $\mathrm{PP}=$ past participles with illegal auxiliary omission; $\mathrm{SC}=$ subordinate clauses including a verb. (A) patient R.O.; (B) patient A.D.; (C) patient E.B.; (D): patient C.M. 
E.B.

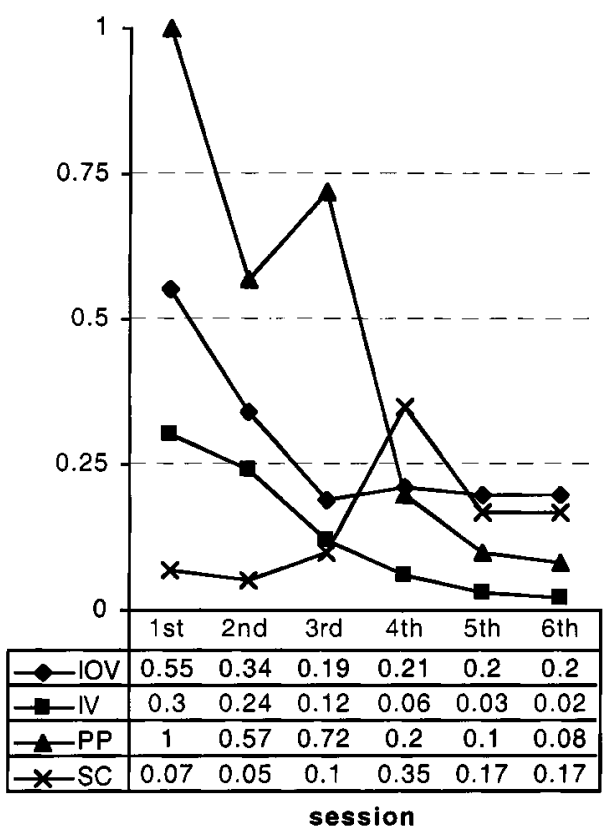

(c)

C.M.

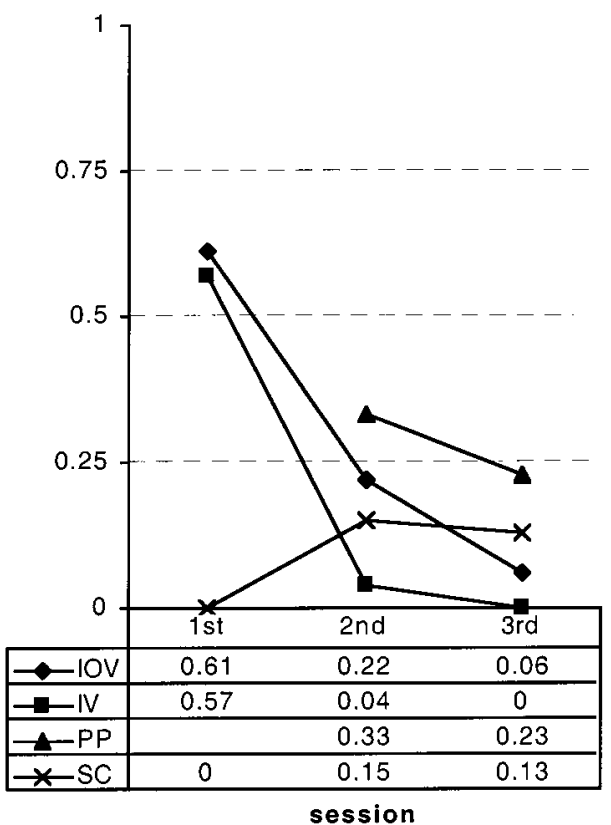

(d)

FIG. 1. Continued 
A similar evolution is attested in C.M.'s speech, where IV drop from 57 to $0 \%$ and IOV decreased from 61 to $6 \%$. A variety of tenses is used from the beginning, $\mathrm{SC}$, initially absent, increase to $15 \%$ of the production, and the omission of auxiliaries decreases from 33 to $22 \%$.

In what follows, some examples of the utterances produced by the patients are reported.

\section{Substitution of Finite Verbs with Infinitives}

E.B. (4/90) [disease onset]: "gamba e braccio funzionavano . . . e poi due giorni dopo, mattina presto no sentire più le gambe e braccio [leg and arm were working ... a and then two days after, morning early NEG feel anymore the legs and arm]'".

\section{Auxiliary Omission}

C.M. (10/90) [disease onset]: “Era quasi notte quando incontrato un cane [It was almost night when seen a dog]'.

\section{Present Instead of Past Tense}

R.O. (04/91) [episode of the Gulf war]: “Un prigioniero parla.. a RAI . . . torna Italia [A prisoner talks to . . TV . . . comes back Italy]".

\section{Direct Discourse in Place of Subordination}

C.M. (10/90) [how he met his girl-friend]: "Ho chiesto: <Hai ragazzo? $>\mathrm{Ha}$ detto: <libera $>$ [(I) asked: $<($ Do you) have boy-friend? $>$ (She) said: < free $>$ '’]

\section{DISCUSSION}

Our results show that at the onset of the disease the clausal structure of agrammatic patients is severely compromised and characterized by the optional omission of verbs, the use of present tense and infinitives replacing finite verbs (IV), and by the auxiliary omission. During recovery, the rate of IV decreased, while that of subordinate clauses (SC) increased. Past tenses started to be used and auxiliaries gradually emerged.

To interpret this set of data, we assume, in line with current linguistic theories, that the clausal representation includes multiple layered functional projections (e.g., Pollock, 1989) (see Fig. 2).

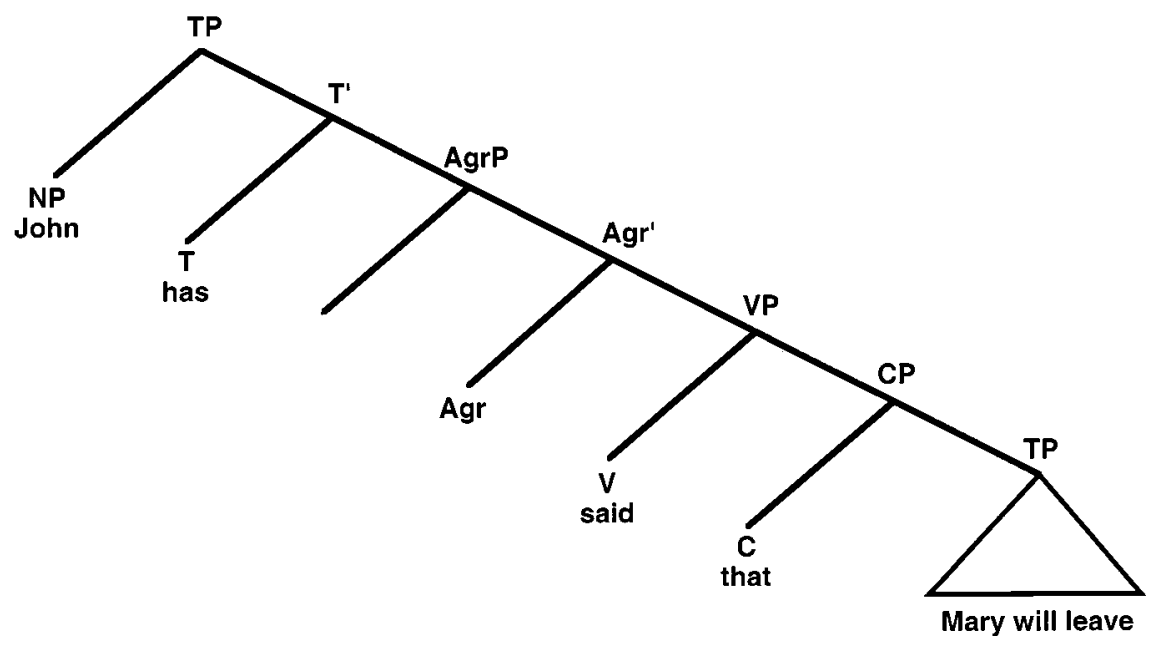

FIG. 2. Clausal structure. 
The Verbal Projection (VP) includes the verb; the Agreement Phrase (AgrP) and the Tense Phrase (TP) carry agreement and tense features, respectively. The Complementizer Projection (CP) expresses information about the clausal type and subordination.

We interpret the initial use of present tense and the lack of subordination as the result of a structure-building strategy occurring during syntactic processing. This strategy limits the recourse to multiple layers of the syntactic tree (TP or CP) and results in the production of sentences, which are illegal in standard Italian, but could be legal in certain registers, such as headlines and diaries (see Haegeman, 1990 for a discussion of these registers; Kolk and Heeschen, 1992 for a discussion of elliptical clauses in agrammatic patients). The limited recourse to syntactic layers may be due either to a primitive syntactic deficit (e.g., Grodzinsky \& Friedmann, 2000) or to a reduced processing capacity (e.g., Linebarger, Schwartz, \& Saffran, 1983; Haarman \& Kolk, 1991; Caplan \& Waters, 1999).

Assuming that phrasal representations are built bottom-up from an array of lexical items, as in the Minimalist Program (Chomsky, 1995), we suggest that layers of the syntactic tree (Fig. 2) become gradually accessible to agrammatic patients during recovery. Initially, only the lower portion of the tree is available. Present tense verbs and infinitives project up to AgrP (under the hypothesis that present tense is not a tense and does project up to TP, as in Giorgi \& Pianesi, 1998). The use of past tense verbs indicates that patients are progressively able to access the TP layer. Finally, the presence of subordinate clauses suggests that also the CP layer has become available.

From a cross-linguistic perspective, our proposal explains why Dutch agrammatic patients find it more difficult to produce finite verbs in second position than in the final position of an embedded clause (Bastiaanse \& van Zonneveld, 1998). To accommodate verbs in second position, $\mathrm{CP}$ must be used. By contrast, finite verbs in final position are located in a lower projection (TP), which is accessible before CP.

A question raised by our account is why patients substitute finite verbs with infinitives. There are two possible explanations. Finite and infinitive clauses have the same syntactic structure but differ morphologically, that is, clauses with IV are finite, but lack the finite morphology. Alternatively, finite and infinitive clauses are not only morphologically but also syntactically different. These accounts make different predictions. According to the latter the use of infinitives is structurally constrained, while according to the former it is not, and the substitution of finite with infinitive forms follow a hierarchical markedness principle (La Pointe, 1985).

E.B.'s data are in favor of the first hypothesis, and those from the other patients do not disconfirm it. During three consecutive sessions, E.B. used subordinate clauses and some of them include an infinitive verb. Moreover, the same patient produced infinitives, not only in positive, but also in negative contexts. These facts suggest that IV clauses are not structurally constrained and that infinitives may occur in the same syntactic environments in which finite verbs are found. The data presented here suggest that in agrammatic patients IV are finite clauses in which verb endings are substituted with unmarked inflectional forms.

As we mentioned, agrammatic speech presents some similarity to children's speech, since in both cases, IV clauses emerge. Is there a unique explanation for the two phenomena? On the basis of an elicitation task, Arabatzi and Edwards (1999) argued against a unitary account. They found that agrammatic patients inflect verbs after negation and produce sentences like "she not goes." In contrast, children do not make such errors (Harris \& Wexler, 1996). Similarly, the evidence from Italian casts doubts on a unitary explanation. First, while infinitives are restricted to certain syntactic environments (i.e., main positive clauses) in children's speech, they are not so restricted in the speech of one of our patient. As we already noticed, E.B. used 
infinitives in subordinate clauses and in negative sentences. Second, Italian speaking children usually do not produce IV clauses, as we pointed out. If the source of IV clauses in agrammatic and child speech were the same, Italian learners should have employed IV clauses on a par with Italian agrammatic patients.

\section{ACKNOWLEDGMENTS}

The study was supported by research grants from the MURST (Ministero dell' Università e della Ricerca Scientifica e Tecnologica) to the authors. A preliminary version of the study was presented at the European Workshop on Cogntive Neuropsychology, Bressanone, January 23-28, 2000.

\section{REFERENCES}

Arabatzi, M., \& Edwards, S. (1999). Optionality and inflections in agrammatic speech. Brain and language, 69, 270-272.

Bastiaanse, R., \& van Zonneveld, R. (1998). On the relation between verb inflection and verb position in Dutch agrammatic aphasics. Brain and Language, 64, 165-181.

Bottari, P., Cipriani, P., \& Chiosi, A.-M. (1996). Root infinitives in Italian SLI children. In Proceedings of the Boston University conference on language development. Sommerville: Cascadilla Press.

Caplan, D., \& Waters, G. S. (1999). Verbal working memory and sentence comprehension. Behavioral and Brain Sciences, 22, 77-126.

Chomsky, N. (1995). The minimalist program. Cambridge: MIT Press.

Giorgi, A., \& Pianesi, F. (1997). Tense and aspect: From semantics to morphosyntax. Oxford: Oxford University Press.

Grodzinsky, Y., \& Friedmann N. (2000). Split inflection in neurolinguistics. In M.-A. Friedemann \& L. Rizzi (Eds.), The acquisition of syntax. Singapore: Longman.

Guasti, M. T. (1993). Verb syntax in Italian child grammar: Finite and nonfinite verbs, Language Acquisition, 3, 1-40.

Haegeman, L. (1990). Understood subjects in English diaries. Multilingua, 9, 157-199.

Haarman, H. J., \& Kolk, H. H. J. (1991). Syntactic priming in Broca's aphasics: evidence for a slow activation, Aphasiology, 5, 1-36.

Hagiwara, H. (1995). The breakdown of functional categories and economy of derivation. Brain and Language, 50, 92-116.

Harris, T., \& Wexler, K. (1996). The optional-infinitive stage in child English: Evidence from negation. In $\mathrm{H}$. Clashen (Ed.), Generative perspective on language acquisition. Amsterdam/Philadelphia: Benjamin.

Kolk, H., \& Heeschen, K. (1992). Agrammatism, paragrammatism and the management of language. Language and Cognitive Processes, 7, 89-129.

Lapointe, S. G. (1985). A theory of verb form use in the speech of agrammatic aphasics. Brain and Language, 24, 100-155.

Linebarger, M. C., Schwartz, M., \& Saffran, E. (1983). Sensitivity to grammatical structure in so-called agrammatic aphasics. Cognition, 13, 361-393.

Lonzi, L., \& C. Luzzatti (1993). Relevance of adverbs distribution for the analysis of sentence representation in agrammatic patients. Brain and Language, 45, 306-317.

Pollock, J.-Y. (1989). Verb movement, universal grammar and the structure of IP. Linguistic Inquiry, 20, 365-424.

Rizzi, L. (1994). Some notes on linguistic theory and language development: The case of root infinitives. Language Acquisition, 31, 371-393.

Torrens, V. (1995). The acquisition of the functional category inflection in Spanish and Catalan. In C. T. Schuetze, J. B. Ganger, \& K. Broihier (Eds.), Working papers in linguistics (Vol. 26). Cambridge, MA: MIT Press.

Wexler, K. (1994). Optional infinitives, head movement and the economy of derivation. In N. Horstein \& D. Lightfoot, Verb movement. Cambridge: Cambridge University Press.

This is doi:10.1006/brcg.2001.1383. 